THE FUNCTIONAL RESIDUAL CAPACITY (FRC) OF INFANTS

1481 WITH RESPIRATORY DISTRESS SYNDROME (RDS) RECEIVING POSITIVE END-EXPIRATORY PRESSURES (PEEP). Peter Richardson and Jeffrey Carlstrom, (Spon. by $\mathrm{H}$. Hill) Dept. of Peds., University of Utah Medical Center, Salt Lake City, UT. RDS is characterized by an inadequate surfactant system which, in the untreated course, leads to progressive atelectasis and decreased FRC. PEEP is used to counter atelectasis and reduce intrapulmonary shunting. FRC is controlled by PEEP yet
PEEP is selected primarily on the basis of blood gases and not FRC. We were concerned that these empirical methods of selectin PEEP for RDS infants frequently result in FRC levels well above or below normal. Therefore, we measured the FRC of 14 prematurely born infants in their second day of life. The infants' mean $( \pm$ SD) gestational age was $31.5 \pm 2.2 \mathrm{wk}$; birth wt $1.6 \pm 0.5 \mathrm{~kg}$; Apgar score $(1 \mathrm{~min}) 4.4 \pm 2.2$. All infants had clinically diag. nosed RDS and were ventilated with the following mean settings: peak inspiratory pressure 23.3 (range 14-34) $\mathrm{cm} \mathrm{H}_{2}$ O) PEEP 4.4 $(3-8) \mathrm{cm} \mathrm{H} O$; rate $42(20-60)$ BPM. Computerized $/ F_{2}$ washout methods, similar to those used in this study, show the FRC of healthy infants this postnatal age to be $17 \pm 2 \mathrm{ml} / \mathrm{kg}$ body wt (Hansen et al, Ped 1970). In our study on RDS infants the FRC ranged from 3 to $33 \mathrm{ml} / \mathrm{kg}$ with a mean of $14.5 \mathrm{ml} / \mathrm{kg}$. Only 3 infants $(21 \%)$ had volumes within one SD of normal. In 5 infants, FRC was greater than one SD above normal and in 6 infants, FRC was greater than one SD below normal. Six infants $(43 \%)$ had FRC values outside of 2 SD of normal. These results suggest that conventional methods of selecting PEEP do not result in the maintenance of normal FRC levels in infants with RDS.

NORMALIZING FUNCTIONAL RESIDUAL CAPACITY (FRC) IN $† 1482$ RDS. P. Richardson, C. Bose, F. Gonzalez, G. King, N. Shaw, and J. Carlstrom, (Spon. by $\left.\frac{H . H i l l}{1}\right)$, Dept. of Peds., Univ. of Utah Med. Center, Salt Lake City, U

PEEP is used in infants with RDS to counter atelectasis and maintain FRC. FRC is controlled by PEEP yet blood gases, not FRC, are the bases for selecting ventilator settings. To test the hypothes is that maintenance of normal FRC leads to improved pulmonary function and reduced mortality, six paired twin lambs delivered prematurely (125-132 days, term is 147) were ventilated, initially, with peak inspiratory pressures (PIP) of $32 \mathrm{~cm}$ $\mathrm{H}_{2} 0,6 \mathrm{~cm} \mathrm{H} \mathrm{H}_{2}$ PEEP, $0.33 \mathrm{sec}$ inspiratory time and 60 BPM while on $160 \% 0$ and then monitored for $24 \mathrm{hr}$. In the control group ventilator settings were adjusted using criteria based on arterial blood gas analyses. In the study group, FRC was maintained within normal limits $(25 \pm 2 S E \mathrm{ml} / \mathrm{kg})$ by adjusting PEEP. The study group FRC on the initial PEEP of $6 \mathrm{~cm} \mathrm{H} 0$ ranged from 9 to $55 \mathrm{ml} /$ group FRC on the initial PEEP of $6 \mathrm{~cm} \mathrm{H}_{2} 0$ ranged from 9 to $55 \mathrm{ml} / 1$
$\mathrm{~kg}$. PEEP required adjustment in 5 of these 6 lambs. Mean PIP, PEEP and mean airway pressures (Pâw) during the $1 \mathrm{st} 8 \mathrm{hr}$ of life were $29.6,5.5$ and $7.1 \mathrm{~cm} \mathrm{H} \mathrm{H}_{2}$ (study group) and $40.4,2.8$ and $6.8 \mathrm{~cm} \mathrm{H} O$ (control). Of the 12 lambs studied, 6 died before 24 hr; 4 cohtrol and 2 from the study group. Even though Paw of the two groups were not different for the $8 \mathrm{hr}$ period, $\mathrm{PaO}_{2} / \mathrm{FiO}_{2}$ of the study group was significantiy greater than the control group $(156 \pm 20$ vs $112 \pm 16 \mathrm{mmHg}$ ). Also, the driving pressure (PIP-PEEP) was less in the study group, yet, $\mathrm{PaCO}_{2}$ was significantly less in the study group than the control group $2(28 \pm 2$ vs $39 \pm 3 \mathrm{mmHg}$ ). These preliminary data suggest that the normalization of FRC improves pulmonary function and may reduce mortality of lambs with RDS. EFFECT OF A SINGLE BREATH OF 100\% OXYGEN ON RESPIRA$\dagger 1483$ Bodani, Don Cates, Leanne Horvath and Henrigue Rigatto. Dept. of Pediatrics, Univ. of Manitoba, Winnipeg, Canada. To determine the effect of a single breath of $100 \% 0_{2}$ on ventilation, 10 term (BW $3360+10 \mathrm{~g}$ (SE); GA $39 \pm .4$ wk, postnatal age $3 \pm .6$ days) and 10 preterm neonates (BW $2020 \pm 60 \mathrm{~g}$, GA $34 \pm 2$ wk, PNA $3 \pm .6$ days) and 10 preterm neonates (BW $2020 \pm 60 \mathrm{~g}$, GA $34 \pm 2$ wk, PNA
$9 \pm 2$ days) were studied during active and quiet sleep states. The single breath method was used to measure peripheral chemoreceptor response. To enhance response and standardize the control period for all infants, $\mathrm{FiO}_{2}$ was adjusted to $16 \pm 0.6 \%$ for a control $\mathrm{O}_{2}$ saturation of $83 \pm 1 \%$. After 1 minute of control in each sleep state, each infant was given a single breath of $\mathrm{O}_{2}$ followed by $21 \% \mathrm{O}_{2} . \dot{\mathrm{v}}_{\mathrm{E}}, \mathrm{V}_{\mathrm{T}}, \mathrm{f}, \mathrm{P}_{\mathrm{A}} \mathrm{O}_{2}, \mathrm{P}_{\mathrm{A}} \mathrm{CO}_{2}, \mathrm{O}_{2}$ saturation (ear oximeter) and $\mathrm{TCPO}_{2}$ were measured. $\mathrm{V}_{\mathrm{E}}$ always decreased with inhalation of $\mathrm{O}_{2}$ $\mathrm{TcPO} 2$ were measured. $\mathrm{V}_{\mathrm{E}}$ always decreased with inhalation of
$(\mathrm{p}<0.01)$. In quiet sleep, the decrease in $\mathrm{V}_{\mathrm{E}}$ was less in term $(\mathrm{p}<0.01)$. In quiet sleep, the decrease in $\mathrm{V}_{\mathrm{E}}$ was less in term
$(14 \%)$ than in preterm $(40 \%)$ infants $(\mathrm{p}<.001)$. Decrease in $\mathrm{V}_{\mathrm{E}}$ (14\%) than in preterm $(40 \%)$ infants $(p<.001)$. Decrease in $V_{E}$
was due primarily to a drop in $V_{T}$ in term infants as opposed to a fall in $f$ and $V_{T}$ in preterm infants $(p<0.05)$. Apnea, as part of the response, was more prevalent in preterm than in term infants. In active sleep the decrease in $\dot{V}_{E}$ was similar both among term (19\%) and preterm (21\%) infants ( $p>0.5)$. These results suggest greater peripheral chemoreceptor response in preterm than in term infants, reflected by a more pronounced decrease in $\dot{V}_{E}$ with $0_{2}$. The results are compatible with a more powerful peripheral chemoreceptor contribution to breathing in powerful peripheral chemorecepto
preterm than in term infants.
01484 IN VIVO LIPID PEROXIDATION IN NEWBORN RABBITS: EFFECT Departicine, University of Iowa Hospitals and Clinics Expired ethane and pentane are sensitive in vivo monitors of lipid peroxidation. The present study examined the effect of vitamin $E(E)$ on lipid peroxidation in newborn rabbit pups exposed to mormoxia (A) or hyperoxia $\left(\mathrm{O}_{2}\right)$. All pups were given parenteral normoxia (A) or hyperoxia $\left(\mathrm{O}_{2}\right)$. All pups were given parenteral
fluid (electrolytes and glucose) and were treated with elther E ( $100 \mathrm{mg} / \mathrm{kg} \alpha$-tocopherol IV) or placebo. $0_{2}$ exposure did not alter expired pentane levels in exther the $\mathrm{E}-$ or placebo-treated pups $\left(3.3\right.$ pmoles $/ 100 \mathrm{~g} / \mathrm{min}$ in $\mathrm{O}_{2}$ vs 4.1 pmoles $/ 100 \mathrm{~g} / \mathrm{min}$ in A). Expired pentane levels were significantly reduced in E-treated $\mathrm{A}$ or $\mathrm{O}_{2}-$ exposed pups compared to placebo-treated $\mathrm{A}$ or $\mathrm{O}_{2}$-exposed pups
$(1.6 \mathrm{pmoles} / 100 \mathrm{~g} / \mathrm{min}$ in $\mathrm{E}$ vs $6.6 \mathrm{pmoles} / 100 \mathrm{~g} / \mathrm{min}$ in placebo). Lung $E$ levels were $162 \pm 42 \mu \mathrm{g} \alpha$-tocopherol/g in E-treated vs 4.2 $+6 \mu \mathrm{g} / \mathrm{g}$ in controls (mean $\pm \mathrm{SD}$ ). Expired ethane levels were not different among the four treatment groups. Animals given only parenteral fluid had a $13 \% 3$-day mortality in $0_{2}$ vs $0 \%$ in $\mathrm{A}$. Elevated expired pentane levels ( 300 pmoles $/ \mathrm{kg} / \mathrm{min})$ in an infant on parenteral lipid emulsion were not altered by $E$ therapy $(100 \mathrm{mg} / \mathrm{kg} \alpha$-tocopherol dally p.o. x 3). These data show that a single $100 \mathrm{mg} / \mathrm{kg}$ IV dose of $\mathrm{E}$ significantly increased lung $\mathrm{E}$ levels and reduced expired pentane in newborn rabbits given only parenteral fluids. $\mathrm{O}_{2}$ did not effect expired ethane or pentane levels but did result in lung injury and mortality. Oxygen toxicity may arise from mechanisms other than those associated with lipid peroxidation. (Supported by NIH GM12675 and PMA Fellowship.)
THE PRENATAL DEVELOPMENT OF NEONATAL MOTOR RHYTHMS. S. Robertson (Spon. by J. Kennel1), Dept. Peds, Case †1485 S. Robertson (Spon. by J. Kennel1), Dept. Peds, Ca spontaneous fetal movement (FM) is essential for normal development of muscles and joints, and the associated neural activity may play a role in the selection of synapses in central motor circuits. A common property of embryonic and FM in many species is cyclic occurrence, with a period of $-1-10$ minutes. Similar motility patterns have recently been described in the human neonate and fetus near term. To determine whether cyclic motility in the human appears only near birth, or emerges earlier as in other species, 22 normal fetuses were studied biweekly until birth (at 37-42 wk, all AGA), beginning at 21-34 wk gestation. FM was detected by 2 pressure transducers on the mother's abdomen. Each analog FM record was digitized in $5 \mathrm{sec}$ intervals during $12-41 \mathrm{~min}(29 \pm 7$, mean \pm SD) of fetal activity free of major artifacts. Spectral analysis revealed significant $(p<.001)$ cyclic patterns in 84/87 FM records, including $4 / 5$ fetuses studied at $21-24 \mathrm{wk}$. The length of the motility cycles was $0.5-7.7 \mathrm{~min}(3.3 \pm 1.7)$, and did not change with gestation. The proportion of FM variance accounted for by motility cycles between 1.0 and 5.5 min increased modestly but significantly $(p<.001)$ from $25 w k(.33 \pm .07)$ to 33 wk $(.41 \pm .05)$. The existence of consistent and strong cyclic motility throughout the second half of gestation suggests it is more than a transient adaptation to the perinatal period. Cyclic activation appears to be a basic property of developing motor circuits in many species, including the human, and its consistent absence may therefore signal compromised CNS function in the fetus.

\section{$\uparrow 1486$} WHOLE BLOOD VISCOSITY DETERMINED BY PLASMA VOLUME: $O$. Linderkamp, D.W. Roloff. Dept.of Pediatrics, niv. of Munich, 8000 Munich, West Germany (spon. by W.F. Howatt) Therapeutic decisions in the management of neonatal hyperviscosity are of ten made on the basis of hematocrit (Het) values only. However, in tubes with the diameter of arterioles, whole blood viscosity (WBV) increases also with plasma viscosity (PV), red blood cell (RBC) aggregation and impaired RBC deformability. In order to determine the correlation between total plasma protein (TPP) as a measure of PV, and Het at various mean corpuscular volumes (MCV) on a WBV of $4.2 \mathrm{cP}$ previously found to be clinically significant, we adjusted the placental blood of 20 premature and 10 term infants, and the venous blood of 10 adults to a Hct between 50 and $70 \%$ and measured TPP and WBV $(100 \mu \mathrm{m}$-capillary viscometer). From these data a nomogram for WBV

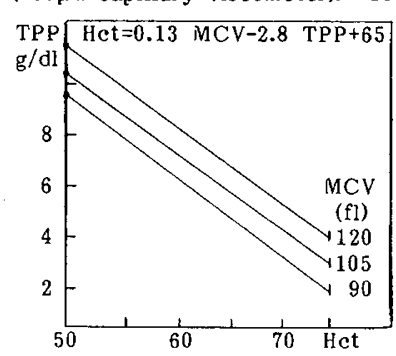
$=4.2 \mathrm{cP}$ was constructed. Thus, a plo for TPP and Het below the appropriate MCV line indicates a
WBV with a lower risk for symptomatic hyperviscosity. The regression equation expresses the critical Het for this WBV as it is influenced by TPP and MCV. It will be noted that certain therapeutic measures e.g., transfusions with plasma, albumin, or RBC with their plasma, albumin, or RBC with their
attendant change in TPP and MCV attendant change in TPP and $\mathrm{MCV}$
may alter whole blood viscosity unfavorably. 